Cover: Lake Martin, south-central Louisiana (photograph by Gabrielle Bodin, U.S. Geological Survey). 


\section{The Wetland and Aquatic Research Center Strategic Science Plan}

Open-File Report 2016-1193

U.S. Department of the Interior

U.S. Geological Survey 


\section{U.S. Department of the Interior SALLY JEWELL, Secretary}

\section{U.S. Geological Survey Suzette M. Kimball, Director}

\section{U.S. Geological Survey, Reston, Virginia: 2017}

For more information on the USGS - the Federal source for science about the Earth, its natural and living resources, natural hazards, and the environment—visit http://www.usgs.gov or call 1-888-ASK-USGS.

For an overview of USGS information products, including maps, imagery, and publications, visit http://www.usgs.gov/pubprod/.

Any use of trade, firm, or product names is for descriptive purposes only and does not imply endorsement by the U.S. Government.

Although this information product, for the most part, is in the public domain, it also may contain copyrighted materials as noted in the text. Permission to reproduce copyrighted items must be secured from the copyright owner.

Suggested citation:

U.S. Geological Survey, 2017, The Wetland and Aquatic Research Center strategic science plan: U.S. Geological Survey Open-File Report 2016-1193, 17 p., https://doi.org/10.3133/ofr20161193.

ISSN 2331-1258 (online) 


\section{Contents}

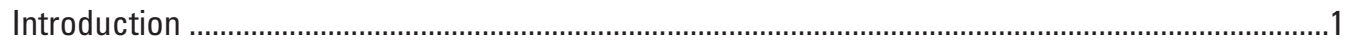

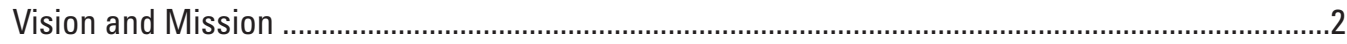

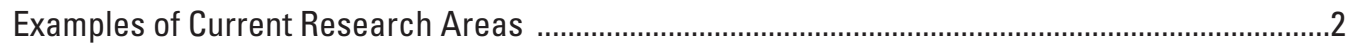

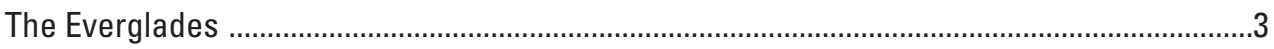

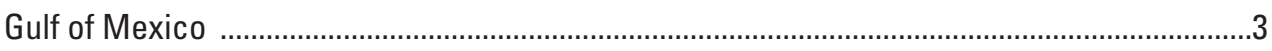

Southeastern U.S. Freshwater and Estuarine Habitats ..........................................................

Watersheds and Coastal Environments of the World ...........................................................

Science Strategy and Research Directions ...............................................................................

Goal 1: Provide actionable science needed to conserve and restore plant, fish, and wildlife populations and communities ..............................................................................

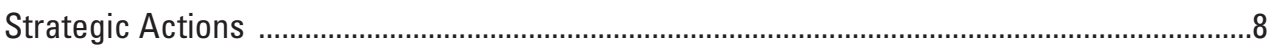

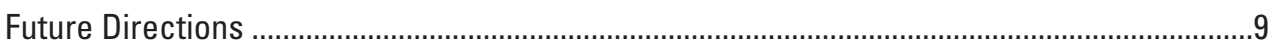

Goal 2: Provide science needed to detect, understand, control, and mitigate the risks and impacts of nonindigenous species and pathogens ......................................................

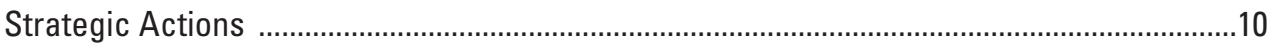

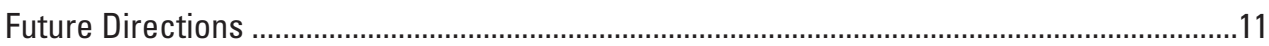

Goal 3: Improve the understanding of wetland and aquatic ecosystem structure, function,

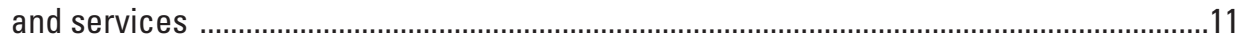

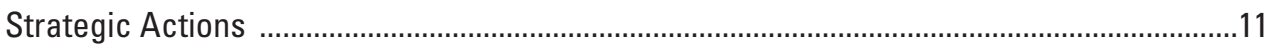

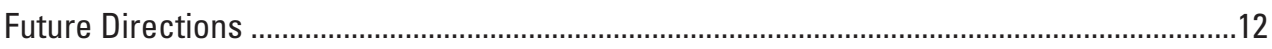

Goal 4: Provide the science needed to better characterize, monitor, and prepare for the

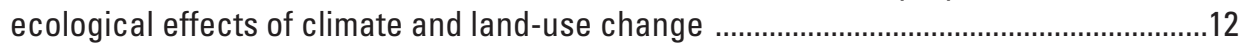

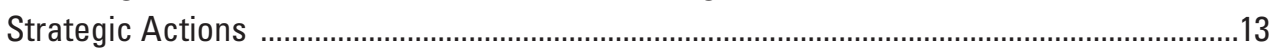

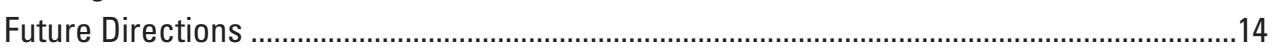

Goal 5: Apply interdisciplinary science to enhance strategies for management,

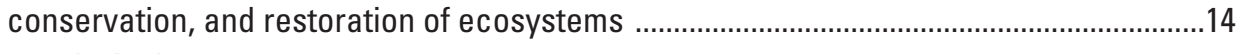

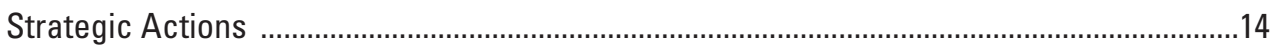

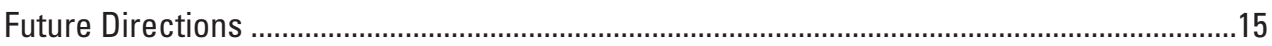

Goal 6: Provide science to improve ecological understanding and enhance landscapeand seascape-scale strategies for ecological management, conservation, and

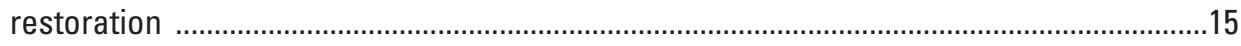

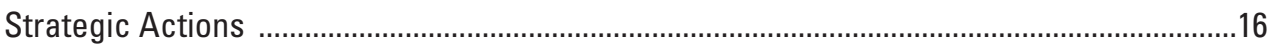

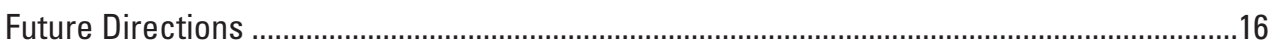

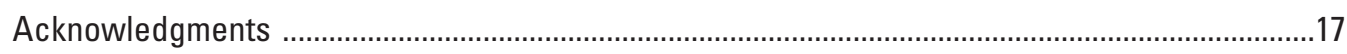

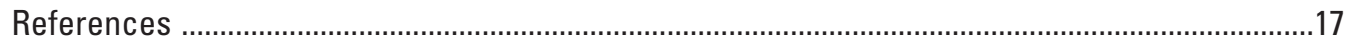

\section{Figures}

1. Map showing locations of the U.S. Geological Survey Wetland and Aquatic Research Center, created from the merger of the Southeast Ecological Science Center and the National Wetlands Research Center in 2015

2. Map showing some of the world's megadeltas dealing with coastal sustainability issues

3. Diagram showing Wetland and Aquatic Research Center science partnerships and alignment with Federal, State, and other governmental agencies and other partners 



\section{The Wetland and Aquatic Research Center Strategic Science Plan}

\section{Introduction}

The U.S. Geological Survey (USGS) Wetland and Aquatic Research Center (WARC) has two primary locations (Gainesville, Florida, and Lafayette, Louisiana) and field stations throughout the southeastern United States and Caribbean (fig. 1). WARC's roots are in U.S. Fish and Wildlife Service (USFWS) and National Park Service research units that were brought into the USGS as the Biological Research Division in 1996. Founded in 2015, WARC was created from the merger of two long-standing USGS biology science Centers - the Southeast Ecological Science Center and the National Wetlands Research Center- to bring together expertise in biology, ecology, landscape science, geospatial applications, and decision support in order to address issues nationally and internationally. WARC scientists apply their expertise to a variety of wetland and aquatic research and monitoring issues that require coordinated, integrated efforts to better understand natural environments. By increasing basic understanding of the biology of important species and broader ecological and physiological processes, this research provides information to policymakers and aids managers in their stewardship of natural resources and in regulatory functions.

This strategic science plan (SSP) was developed to guide WARC research during the next 5-10 years in support of Department of the Interior (DOI) partnering bureaus such as the USFWS, the National Park Service, and the Bureau of Ocean Energy Management, as well as other Federal, State, and local natural resource management agencies. The SSP demonstrates the alignment of the WARC goals with the USGS mission areas, associated programs, and other DOI initiatives. The SSP is necessary for workforce planning and, as such, will be used as a guide for future needs for personnel. The SSP also will be instrumental in developing internal funding priorities and in promoting WARC's capabilities to both external cooperators and other groups within the USGS.
One of the greatest outcomes of the merger of the SESC and NWRC into WARC is the ability to improve ecological understanding from an organismic to landscape level for enhancing resource management, conservation, and restoration. The merger enabled an effective coupling of expertise in aquatic fauna, wetland structure and function, and landscape science to holistically address important ecological issues. For example, the merger provides an opportunity to more strategically link the biotic and abiotic components of a particular ecosystem to answer specific questions; to link biological modeling experts in Florida with the spatial data analysis and visualization capacity in Louisiana; to link remote sensing and oceanography expertise with ecologists working on coral reefs and mangroves in the Virgin Islands; or to conduct comprehensive assessments of restoration activities that include multiple trophic levels. Also resulting from the merger is the combining of staff in Florida and Louisiana with similar expertise of certain tools, such as genetics and advanced modeling, but with different foci in previous research - the resulting expertise is now over a greater range. WARC scientists will now be able to incorporate, for example, organismic characteristics such as movement and habitat utilization into coupled models that predict population changes at ecosystem or landscape and seascape levels. Another major benefit of the merger is the newly combined geographic extent of WARC that allows us to more effectively respond to management concerns across the entire Gulf of Mexico region. In addition to this enhanced ability to address issues, the merger also allows opportunities to encourage innovative science and to experiment on topics that go beyond simply answering conservation questions. For example, rather than simply monitoring the spread of invasive lionfish, WARC scientists could explore options for eradication, whether it be genetically or by sophisticated trapping. 


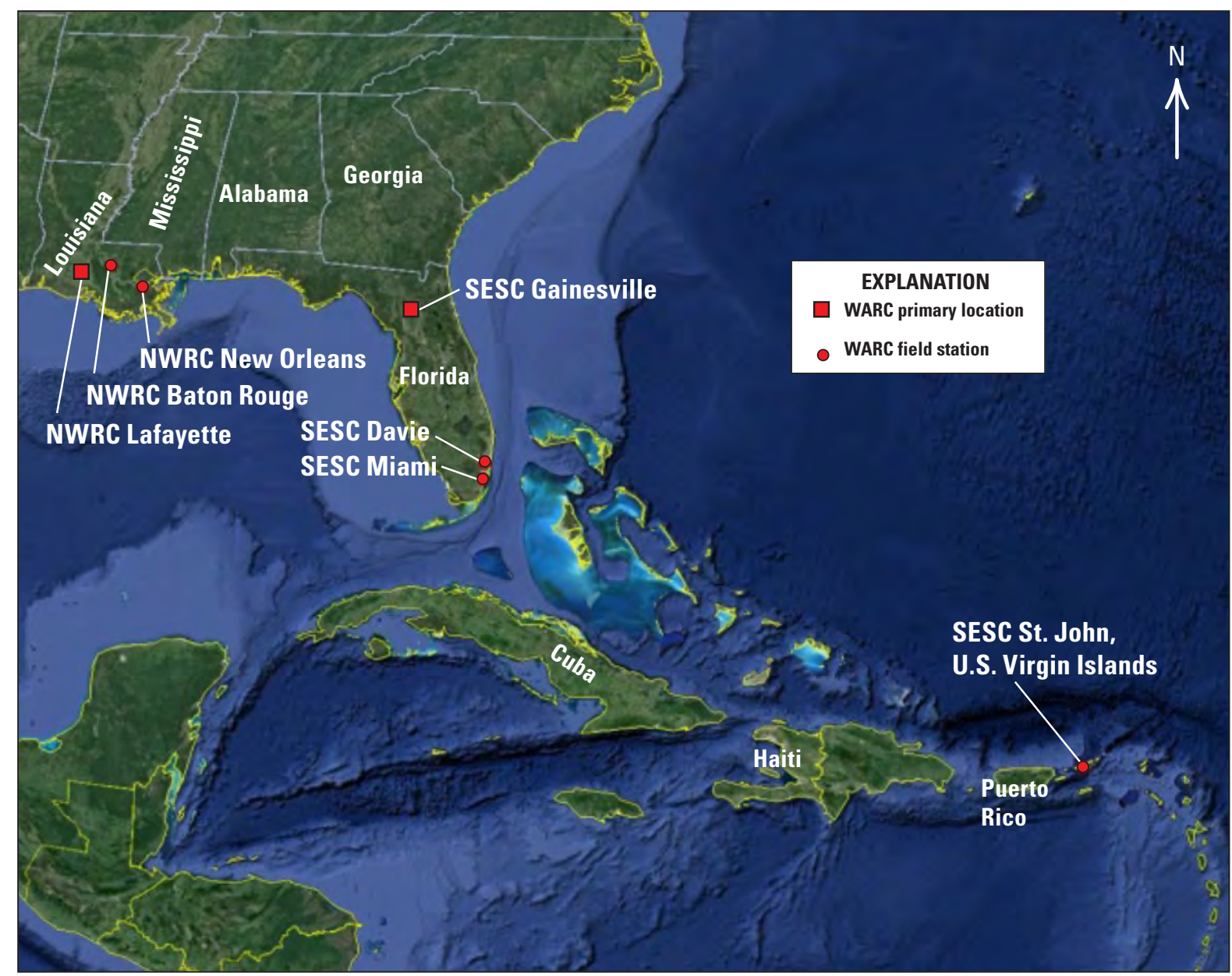

Base map data from Google Earth, May 2016

Figure 1. Locations of the U.S. Geological Survey (USGS) Wetland and Aquatic Research Center (WARC), created from the merger of the Southeast Ecological Science Center (SESC) and the National Wetlands Research Center (NWRC) in 2015.

\section{Vision and Mission}

The vision of WARC is to expand our leadership role as a preeminent source of wetland and aquatic science and technology. To achieve this vision, we will strive to maintain a highly flexible and adaptive research and support staff that can effectively respond to emerging issues in natural resource conservation and management. WARC will continue to emphasize conducting cost-effective and highly competitive interdisciplinary, team-oriented research by utilizing scientific expertise from within and outside WARC.

Our mission is to conduct relevant, objective, and applied scientific research; develop new approaches and technologies; and disseminate scientific information needed to understand, manage, conserve, and restore wetlands and other aquatic and coastal ecosystems and their associated plant and animal communities both nationally and internationally, with an emphasis on the southeastern United States and the Gulf of Mexico. To that end, WARC scientists have developed expertise and partnerships with managers in both freshwater and marine environments around the world.

\section{Examples of Current Research Areas}

WARC scientists contribute to major conservation and restoration initiatives worldwide with research sites that include aquatic habitats such as rivers and streams, freshwater and coastal wetlands, coral reefs, mangrove forests, and the deep sea. 


\section{The Everglades}

The Everglades in southern Florida is one of the world's unique wetland ecosystems. This 3,500-square-mile wetland ecosystem is the only subtropical wetland in North America (Douglas, 2007) and the only wetland in the United States that is listed both as a United Nations Educational, Scientific and Cultural Organization (UNESCO) World Heritage site and as a UNESCO biosphere reserve. Everglades National Park protects more than 2,300 square miles of this wetland and is the second largest national park in the United States. The park encompasses the downstream terminus of the freshwater drainage features in a large hydrologic system, as well as large expanses of coastal oligohaline marshes, mangrove swamps, and the offshore benthic communities of Florida Bay. Prior to human intervention, The Everglades was characterized as a shallow, slow-moving

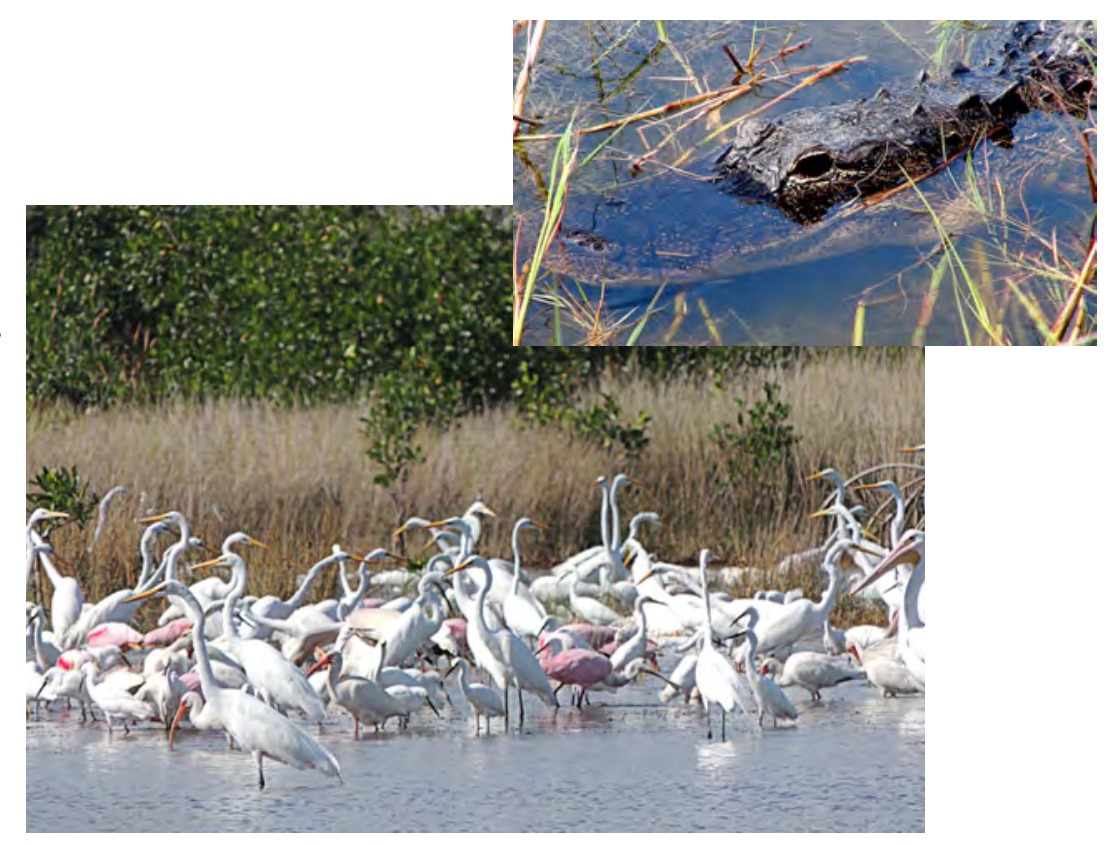
river approximately 60 miles wide that traversed more than 100 miles to Florida Bay and the Gulf of Mexico. Often termed "sheetflow," this wide expanse of slow-moving water helped shaped The Everglades ecosystem as it is known today.

The Comprehensive Everglades Restoration Plan (CERP) to restore sheetflow and the ecosystem functioning of The Everglades began in earnest in 1995 and continues to this day. Led by multiple Federal and State agencies, CERP represents the largest ecosystem restoration project ever undertaken. WARC and other USGS scientists have led key scientific research projects designed to inform CERP engineering and provide rigorous studies on the ecological impacts of restoration. These efforts have led to improved means of forecasting the potential ecological impacts of alternative restoration plans, to monitoring data for adaptive management, and to information on important indicators of ecosystem health and functioning. Recently, WARC scientists helped formulate the landscape-scale design of the new Everglades Headwaters National Wildlife Refuge and Conservation Area. WARC is committed to continued support of the scientific efforts to restore and protect The Everglades ecosystem, including important DOI lands such as the Arthur R. Marshall Loxahatchee National Wildlife Refuge, Big Cypress National Preserve, Biscayne National Park, and Everglades and Dry Tortugas National Parks.

\section{Gulf of Mexico}

The Gulf of Mexico's nearly 600,000 square miles of area and nearly 3,800 miles of coastline (Moretzsohn and others, 2016) offer vast coastal, nearshore, and deep marine habitats for a great diversity of biota. Gulf fisheries are some of the most diverse and productive in the world, and the gulf provides migration or movement corridors for a variety of fauna. Seagrass beds along the coast are habitat for many types of large and small marine biota and also provide forage for larger animals such as the manatee and sea turtles. A great concern, though, is that coastal land loss and habitat degradation are occurring on the Gulf of Mexico coast at alarming rates.

Freshwater drains into the gulf from 33 major rivers in the United States and others in Mexico and Cuba, supporting the coastal ecosystems but also introducing threats and stressors such as organic and inorganic contaminants, turbidity, and diminished flows. Extensive oil and natural gas exploration and production in the northern gulf, along with natural and induced seeps, enhance the potential for environmental contamination of coastal and offshore habitats and wetland submergence. Naturally occurring, harmful algal blooms frequently are found in gulf coastal areas and have caused adverse effects and mortality to various at-risk species. Changing climatic conditions and additional nutrients from runoff may be enhancing the frequency and severity of the blooms while also contributing to the expansion of the gulf's hypoxic zone. 


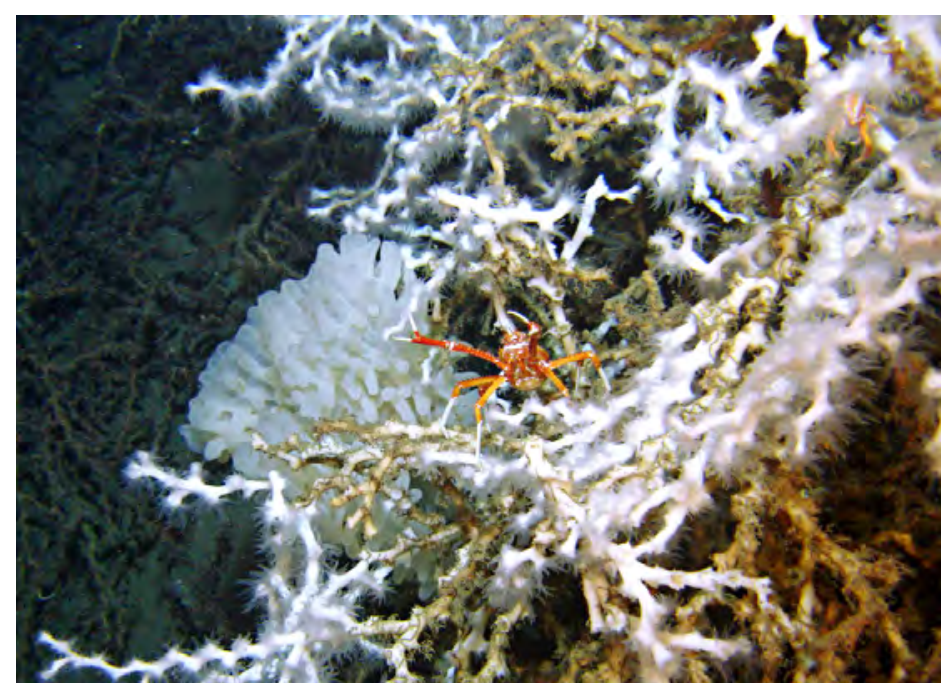

WARC researchers are addressing research topics such as coastal wetland loss and habitat resiliency, conservation of imperiled species, effects of hydrocarbons on coral reefs and other marine and estuarine animals and habitats, and the effects of climate and land-use change on coastal ecosystems. USGS researchers and specifically those from WARC play a key role in Louisiana coastal restoration efforts through implementation of the Coastal Wetlands Planning, Protection and Restoration Act (CWPPRA) and the Coastwide Reference Monitoring System (CRMS), a multiagency effort that has led to the restoration of more than 110,000 acres of coastal wetlands in Louisiana. WARC has expertise and data that are needed to assess the effectiveness of restoration activities and successfully restore and manage natural resources in the gulf region damaged as a result of the Deepwater Horizon oil spill event. Response, assessment, and monitoring activities by WARC staff have also been associated with Natural Resource Damage Assessment (NRDA). WARC is working closely with restoration stakeholders such as the Gulf Coast Ecosystem Restoration Council (RESTORE ${ }^{1}$ Act Council) to implement monitoring frameworks and target research to improve restoration planning and assessment in the gulf. Scientists at WARC, for example, have partnered with groups such as the Gulf of Mexico Alliance (GOMA), the Landscape Conservation Cooperatives (LCCs), and the USFWS Gulf Restoration Program and have provided modeling that is guiding strategic restoration activities.

\section{Southeastern U.S. Freshwater and Estuarine Habitats}

An astounding diversity of species is found in the wetland and aquatic habitats in the southeastern United States. With a rapidly growing human population, climate change, and widespread land-use changes, threats to aquatic habitats and biological resources are increasing. Alteration and degradation of forest and wetland ecosystems, such as in the Lower Mississippi River Alluvial Valley, are nearly unprecedented in both scale and scope. Whether streamflow regimes are modified because of water resource management actions or because of climatically driven shifts in amounts and timing of precipitation, the ecological responses may include changes in the ability of wetland and aquatic ecosystems to support fish and wildlife populations. The conversion of riparian forests in the valley, primarily to agriculture, has caused loss and degradation of many ecosystem functions and services including plant and animal habitat, flood storage, nutrient and sediment retention, and carbon storage. Assessing and forecasting ecological responses to changes in streamflow regimes or hydroperiods form a key component of sustainable water management, and science-driven options are needed for making sound water management decisions. The WARC has invented and applied animal biomarkers of exposure and effect around the country that predict and assess ecosystem function.

Partnerships within the DOI, as well as with other conservation and research organizations, provide additional scientific integrity and financial resources for studying a wide variety of freshwater organisms. For example, effective conservation of Etheostoma okaloosae (Okaloosa darter), endemic to Eglin Air Force Base in northwest Florida, requires an understanding of temporal and spatial variability in population size and age structure. Using innovative sampling and biometric techniques over the past two decades, WARC and Loyola University New Orleans researchers utilized new methods for estimating population size, and the estimates allowed for the USFWS to downlist the species from endangered to threatened status in 2011. As another example,

\footnotetext{
${ }^{1}$ Resources and Ecosystems Sustainability, Tourist Opportunities, and Revived Economies of the Gulf Coast States Act, https://www.restorethegulf.gov/.
}

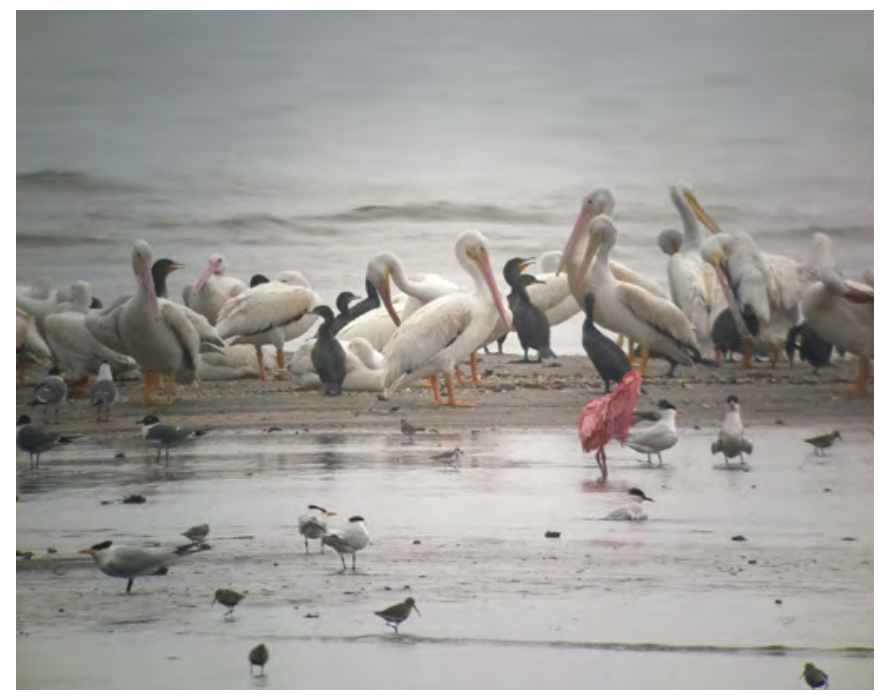


habitat loss and alteration have contributed to Ambystoma cingulatum (Flatwoods salamander) population declines in the southeastern United States, especially notable at the St. Marks National Wildlife Refuge in the Florida Panhandle, where only 20 percent of original breeding ponds remain. WARC scientists along with the USFWS, The Nature Conservancy, and Coastal Plains Institute staff used structured decision making and an adaptive management framework to strategize regarding Flatwoods salamander habitat restoration. WARC has needed expertise and data to understand and effectively restore and manage the Lower Mississippi River Alluvial Valley and is working closely with the USFWS, the U.S. Army Corps of Engineers, and other stakeholders to build a framework for research and management to restore the Nation's great flood plain. As a final example, freshwater mussels have emerged as one of the most imperiled groups of organisms in North America and the focus of several recent listing priorities for the USFWS. WARC researchers led a cooperative study with State and Federal partners to fill knowledge gaps for several mussel species currently under consideration for Federal listing, including Medionidus walkeri (Suwannee moccasinshell). The project focused on characterizing early life history requirements and quantifying spatiotemporal changes in the species' distribution to assist managers facing listing decisions and critical habitat designations.

\section{Watersheds and Coastal Environments of the World}

Coastal environments are threatened on a global scale (fig. 2) as human populations and development pressures increase. These coastal areas also are highly susceptible to natural disasters. In addition, entire watersheds and critical processes are threatened by land-use practices and human development. WARC will continue to develop scientific partnerships across the United States and with other countries (including active research collaborations in Vietnam, Micronesia, Turkey, India, China, Laos, and Cambodia, as well as many other countries in Europe and Africa) to facilitate research and cooperation to understand large ecosystem function and processes and impacts to dependent fish and wildlife populations. Example studies are freshwater fish habitat and passages in eastern Asia, manatee health assessments and genetic studies throughout the Caribbean, and adaptive harvest management and flyway development of Anser brachyrhynchus (pink-footed goose) in northwestern Europe. Comparative studies across the globe allow landscape-level hypothesis generation and testing that will ultimately drive the management, policy decisions, and regulations related to land and water resource management. Research on this scale is required to investigate the processes and impacts of large-scale ecological changes, such as sea-level rise and climate change, and it is critical to examine ecosystems that are affected by different biotic and abiotic factors. Expanding research and cooperative efforts to far reaching ecosystems allows for new hypothesis generation and testing at a landscape scale.

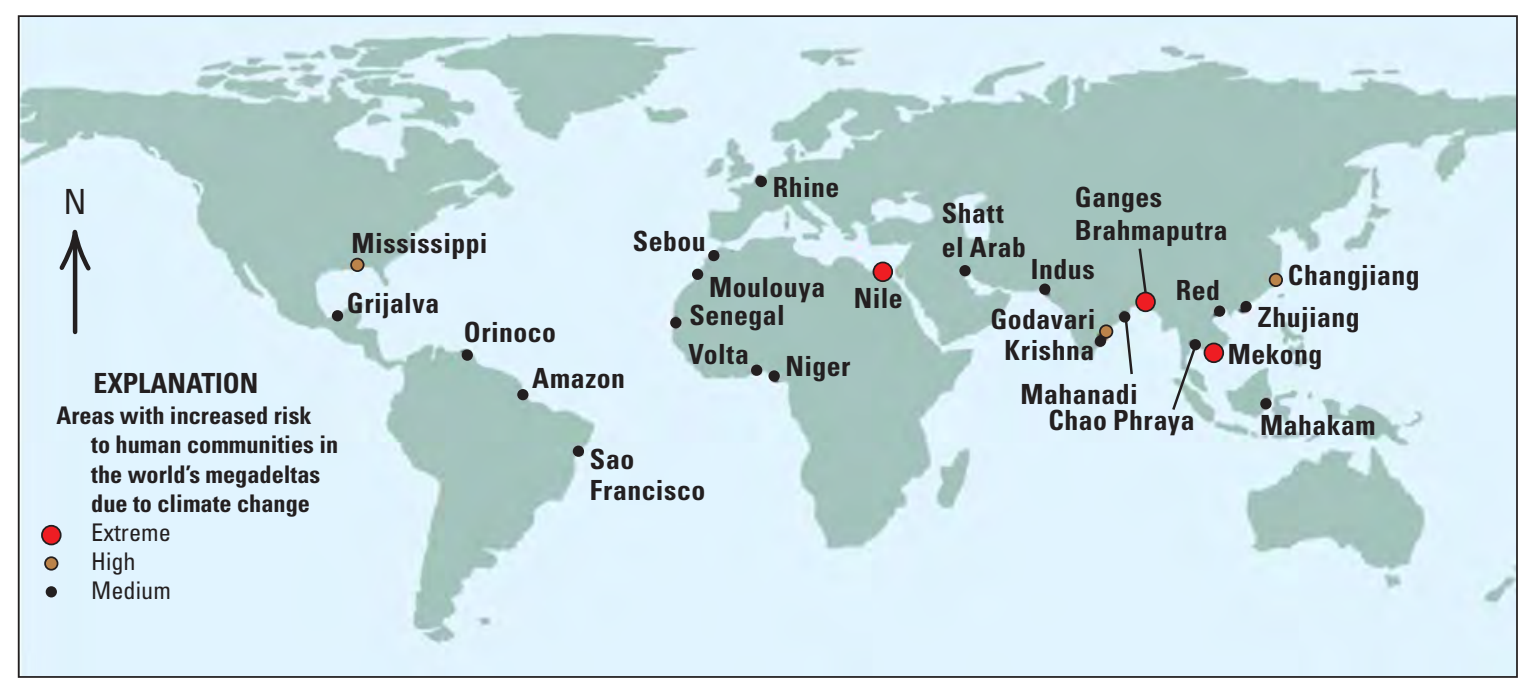

Figure 2. The Intergovernmental Panel on Climate Change (IPCC) Fourth Assessment Report (available at https://www.ipcc.ch/report/ar4//) highlighted the increased risk to human communities in the world's megadeltas due to climate change. Many of these areas are dealing with coastal sustainability issues including compromising among flood protection, food security, water quality, and biological diversity. Wetland and Aquatic Research Center (WARC) researchers are already working in many of these systems. (Modified from Nicholls and others, 2007, chap. 6, fig. 6.6.) 
All of the WARC science goals are pursued according to a strategy that is closely aligned with the 2013 USGS Ecosystems Mission Area science strategy.

1. Improve understanding of ecosystem structure, function, and processes

2. Advance understanding of how drivers influence ecosystem change

3. Improve understanding of the services that ecosystems provide to society

4. Develop tools, technologies, and capacities to inform decision making about ecosystems

5. Apply science to enhance strategies for management, conservation, and restoration of ecosystems

The development of innovative tools, approaches, and technologies is central to WARC's ability to answer novel research questions and deliver user-friendly results to inform natural resource management decision making. Ecological modeling is used, for example, to help forecast impacts of ecosystem restoration and climate change. Advances in geospatial technologies are used in classifying vulnerable coastal and wetland habitats. Adaptive management and structured decision making integrate values-focused thinking and understanding of uncertainty into management decisions ranging from conservation of endangered species to control of invasive species. Desktop and Web tools are used to provide decision support to partner agencies, as well as to communicate science to both decision makers and the public.

\section{Science Strategy and Research Directions}

WARC seeks to provide the observational data, model results, and decision support needed by DOI and subordinate bureaus, other Federal agencies, State-level agencies, and other external collaborators to protect, conserve, and restore our Nation's natural resources. WARC promotes the broader goals of the DOI and the USGS, particularly those identified in the USGS science strategy, "Facing Tomorrow's Challenges: U.S. Geological Survey Science in the Decade 2007-2017" (U.S. Geological Survey, 2007), and those in the Ecosystems Mission Area's "U.S. Geological Survey Ecosystems Science Strategy: Advancing Discovery and Application Through Collaboration" (Williams and others, 2013). WARC science is pursued according to the Ecosystems Mission Area science strategies to enhance partnerships and promote the use of interdisciplinary ecosystem science, enhance modeling and forecasting, and support decision making. Figure 3 illustrates the alignment of WARC science with national-level USGS mission areas and programs and regional-scale initiatives.

Fundamentally, WARC is a hypothesis-driven science organization wherein scientists pursue research from the organismic to landscape scales. This wide range of research was enabled by the merger of the SESC and NWRC, effectively coupling expertise in aquatic fauna, wetland structure and function, and landscape science. The combined strengths of both Centers now provide the unique capability to holistically address important ecological issues, including impacts of stressors such as climate and land-use change, that face natural resource managers.

WARC seeks to foster the development of collaborative research teams with expertise in each facet of this strategy in order to address the issues and challenges facing our Nation's natural resources. Team development might occur, for example, as a result of a request for proposals and can be initiated by either scientists or managers. Above all, this strategy recognizes the importance of synthesis in studies about living resources that range in scope from population level to landscape scale and also include the impacts of stressors over time.

This SSP provides a blueprint for directing WARC's science program over the next 5 years, 2016-2021. The SSP will be the primary source of guidance for base funding allocations, organizational structure, staffing decisions, and decisions about support infrastructure. The SSP was written by a team of scientists and managers drawing on the advice and input of additional WARC scientists.

To measure the effectiveness of this SSP on an annual basis, WARC management will consult with partners and USGS program coordinators to prioritize funding levels and staff commitments towards particular future directions, striving to maximize the impact of our science on conservation of natural resources. An audit of our science can be undertaken in 5 years as part of the next cycle of WARC science planning; the audit will evaluate impact based on metrics in development and will include assessing how our science is used in decision making.

This WARC SSP defines six goals, each followed by a short description, that will guide our Center's research. "Strategic actions" identified beneath each goal describe how the goal will be accomplished in the coming years - in other words, the actions taken to meet the goal. Lastly, "future directions" suggest opportunities for new science needed to achieve each goal, and emphasis will be given to identifying opportunities and seeking funding sources that will support new collaborations among scientists to support interdisciplinary proposals.

WARC scientists face great challenges regarding the volume and complexity of data resulting from collection, analysis, and modeling; they will be looking for novel and efficient means to manage these data. Advanced tools, such as structured decision making and various types of modeling and visualization, allow WARC scientists to communicate science in dynamic and engaging ways. These methods are applicable to many of the strategic actions or future directions for any of the goals below, and their use might be detailed in proposals for application during current or future research projects. 


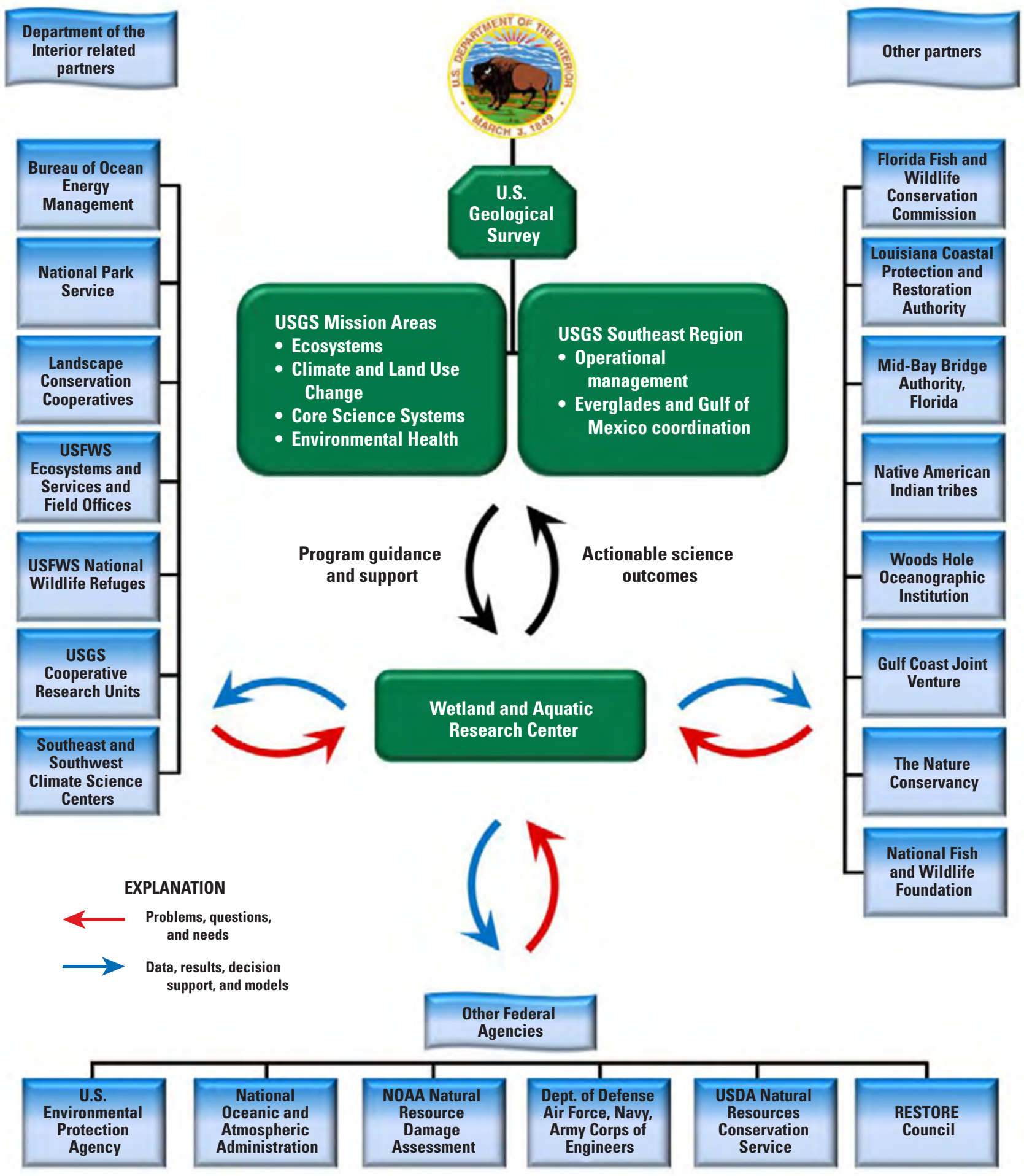

Figure 3. Wetland and Aquatic Research Center (WARC) science partnerships and alignment with Federal, State, and other governmental agencies and other partners. Many other collaborating partners and associations have longstanding affiliations with WARC, such as numerous universities in the United States and the Caribbean, the Smithsonian Institution, and the American Fisheries Society; some have contributed funding in past years. 
The goals of the WARC SSP concern the following:

1. Conservation and restoration of populations and communities

2. Risks and impacts of nonindigenous species and pathogens

3. Ecosystem structure, function, and services

4. Ecological effects of climate and land-use change

5. Strategies for management, conservation, and restoration of ecosystems

6. Landscape and seascape science for holistic "big picture" decision making

\section{Goal 1: Provide actionable science needed to conserve and restore plant, fish, and wildlife populations and communities}

Developing effective conservation strategies for Federal trust resources (which include migratory birds, threatened and endangered species, interjurisdictional fish, certain marine mammals, species of international concern, wetlands, and USFWS lands) is a critical need for resource managers. As plant and animal populations and communities respond to changing conditions, natural resource agencies rely on WARC scientists to provide data and interpret research results to inform their management decisions. Research focuses on identifying factors and processes that influence the persistence of populations and communities, including habitat alteration, landscape modification, climate change, and other stressors. Projects include physiological and morphological assessments, life-history studies, and population- and community-level studies. Efforts also focus on the effectiveness of recovery actions and the development of better decision support tools.

\section{Strategic Actions}

1. Improve understanding of population trends for species of management concern with an emphasis on imperiled species.

- Ensuring the continued survival of species in the face of increasing anthropogenic stressors requires active and intensive management strategies. The results of investigations allow managers to validate assumptions used in conservation planning, compare and contrast potential outcomes of different management strategies, and make decisions by using state-of-the-art models and decision support tools.

2. Develop and test innovative methods for improving the efficiency and accuracy of species surveys and monitoring.

- Assessing the status and trends of plants, fish, and wildlife species is a challenge. The efficiency and accuracy of species population assessments are addressed by WARC scientists through innovative methods and technological advancements. Examples include remote sensing, genetics, citizen science, remote telemetry, new quantitative estimation techniques, and adaptive monitoring approaches that incorporate dynamic factors such as shifting home ranges and habitat patchiness into sampling designs. Improved detection and monitoring efforts are needed, especially for species not well surveyed by conventional methods.

3. Improve understanding of plant community resiliency and fish and wildlife health issues in aquatic and coastal systems.

- The underlying effects of multiple stressors causing changes in health and physiological functions are often poorly understood. Significant effort has focused on understanding the effects of anthropogenic perturbations on coastal and aquatic species, such as the plant and benthic communities affected by the Deepwater Horizon oil spill. Future efforts will be expanded to include the development of techniques to model population-level effects of diseases and other lethal and sublethal stressors (for example, pollinator declines, chytrid fungus, white nose syndrome, contaminants, and pathogens). These assessments are accomplished through laboratory-based experiments and analyses, such as toxicity testing, flow cytometry, and histopathology, but also include fieldwork to understand responses of fish and wildlife populations to environmental stressors.

4. Model and forecast changes in fish and wildlife species of conservation concern affected by climate change, land-use change, contaminants, invasive species, and other stressors. 
- Accurately forecasting the long-term survival of species requires an improved understanding of the factors that have led to past extinctions and the magnitude and potential effects of current and future stressors. WARC studies of wildlife populations focus on species targeted for conservation by DOI bureaus, with emphasis on migratory trust speciesparticularly birds, reptiles, amphibians, mammals, and localized endemic fishes and invertebrates (for example, freshwater mussels). WARC projects allow managers to predict how future land use and climate change may affect these species and allow for better informed management and recovery actions.

\section{Future Directions}

- Use indicator species models for conservation planning and develop new quantitative ecological approaches to inform and forecast the success of large-scale restoration, conservation, and management activities (for example, Gulf of Mexico restoration, Everglades restoration, and Pinus palustris [longleaf pine] restoration).

- Increase capacity in field research and monitoring to address DOI management needs for habitats and species of concern, including freshwater fishes, mussels, amphibians, reptiles, marine mammals, and migratory birds, and to link the connectivity of habitats to particular species of concern.

- Enhance assistance to DOI bureaus for better understanding population trends and effectively managing trust resources as a result of the evergrowing number of at-risk species.

- Develop new research programs in the emerging discipline of movement ecology to address problems associated with habitat fragmentation, climate change, biological invasions, spread of diseases, development of airspace (for example, wind turbines and cell towers), and patterns of pollination. Use of new technologies (for example, tissue isotopes, genetic markers, passive integrated transponder (PIT) tags, very high frequency (VHF) telemetry, geolocators, satellite telemetry, and radar) will allow fish and wildlife to be tracked at finer resolutions and longer distances than currently possible.

- Use "best available science" with decision analysis tools to guide decision makers in the formulation of natural resource management questions and ensure that research directly informs their decision making

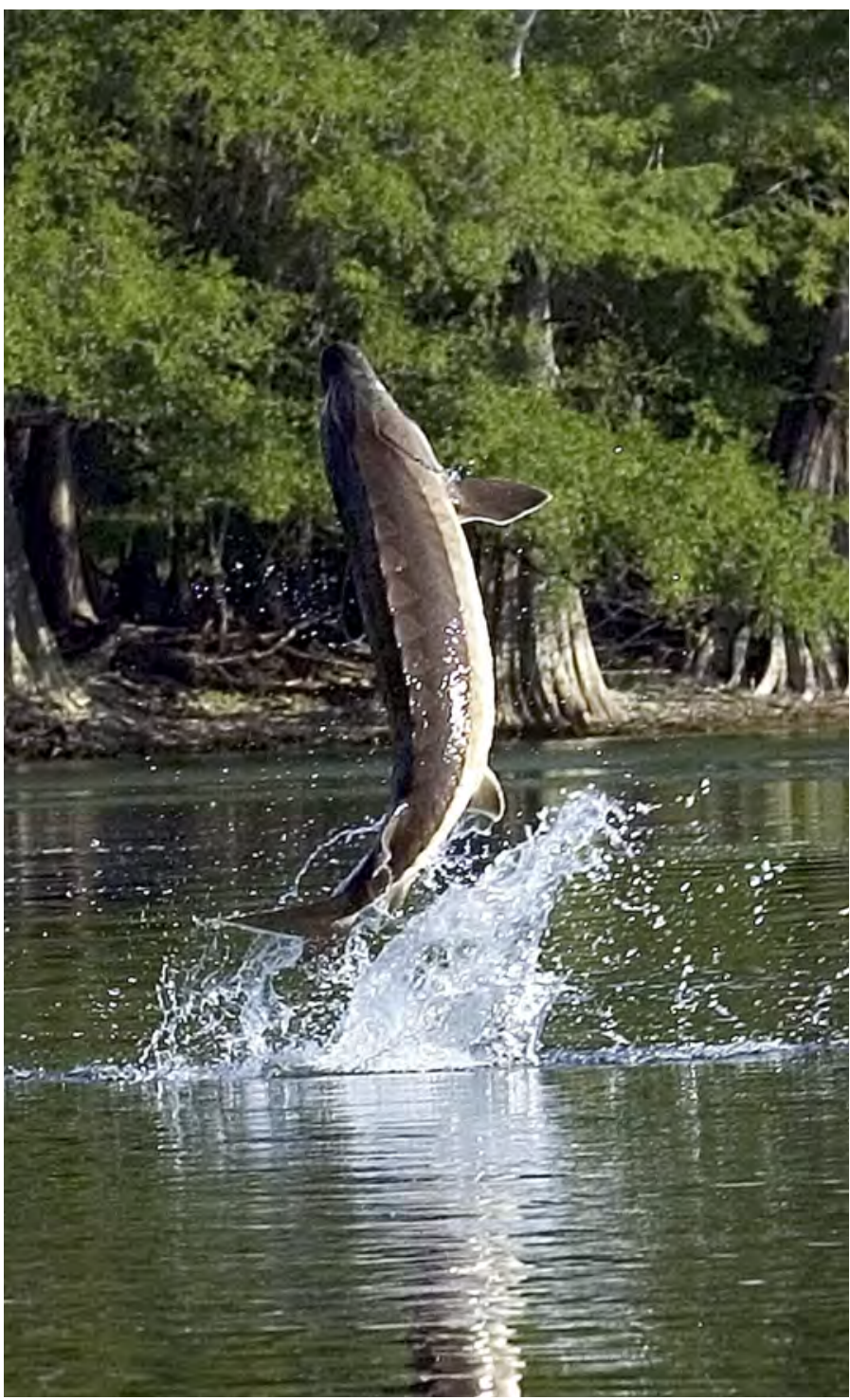
needs.

\section{Goal 2: Provide science needed to detect, understand, control, and mitigate the risks and impacts of nonindigenous species and pathogens}

Economic costs of managing nonindigenous (introduced) species and pathogens in the United States reach into the billions of dollars annually. Many nonindigenous species threaten native species and ecosystems and may introduce pathogens and parasites into native populations. An improved understanding of the risks of introduction and spread, detection and 
control methods, factors controlling dispersal (including climate change and landscape factors), and ecological impacts of nonindigenous species is necessary. WARC research seeks to inform resource management agency strategies for predicting, monitoring, controlling, and mitigating the impacts of nonindigenous species.

\section{Strategic Actions}

1. Document, predict, and monitor the presence and spread of nonindigenous species and pathogens, and assess their risks and impacts on wetlands and aquatic systems and human and wildlife health.

- The early detection and accurate identification of an introduced species are the first steps in its control and eradication. Information on a species' life history characteristics, the natural and anthropogenic factors controlling its survival and dispersal, native and nonindigenous species interactions, and potential for adverse ecological impacts is necessary to assess the risks it poses. Most nonindigenous species researched at WARC are problematic. Ongoing and future research at WARC will contribute to tracking the presence of nonindigenous species in the environment and will improve detection and monitoring techniques, tools for risk assessment, and forecasts of dispersal patterns of nonindigenous wetland and aquatic species across the United States.

2. Develop and assess the effectiveness of management strategies designed to prevent, control, and eradicate nonindigenous species.

- With the ever-increasing number of introductions of nonindigenous species to the United States, the need for new biological, chemical, and mechanical approaches to control these species is also increasing. WARC scientists seek to improve understanding of what is needed to prevent the introductions of nonindigenous species, to control their dispersal, and to eradicate them from the environment, with a focus on species that pose significant risks to wetlands, wildlife, and human health.

- As the numbers of introductions increase, management agencies with limited resources will increasingly be forced to compromise regarding, for example, the level of effort dedicated to monitoring versus control of nonindigenous species,

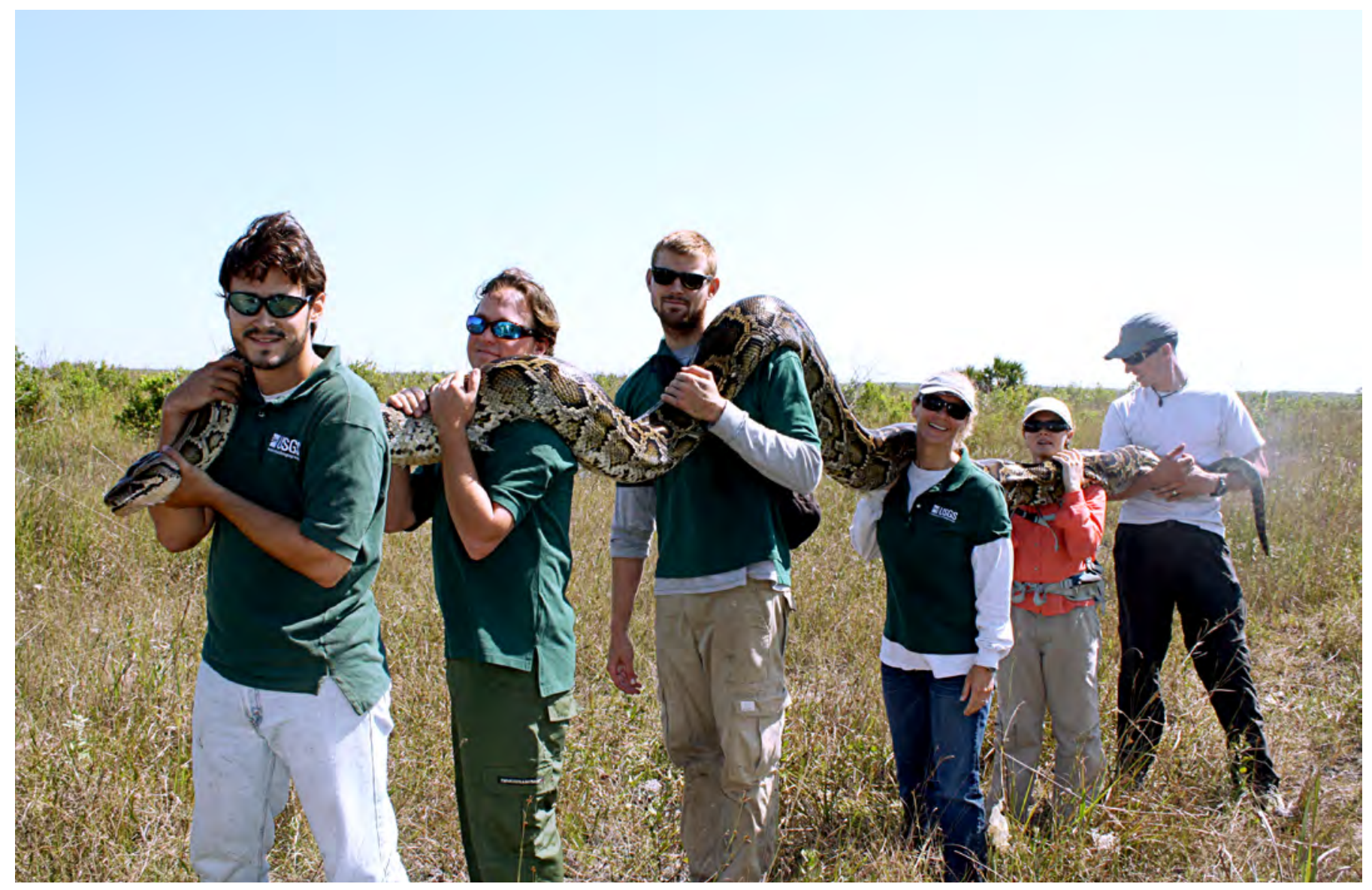


preventing new introductions versus eradicating established species, and prioritizing efforts across multiple species. WARC research is intended to assist agencies in these decision-making processes and to assess the effectiveness of management strategies. WARC scientists seek to provide agency managers with decision support tools such as simulated forecasts of dispersal and impacts, resource-allocation optimization modeling, applications of structured decision making and adaptive management, and integrated pest management approaches.

\section{Future Directions}

- Expand taxonomic methods and expertise in identifying wetland and aquatic organisms, including plants, fish, mussels and other invertebrate species, and wildlife by combining traditional and genetic-based techniques (for example, DNA barcoding).

- Expand the use of eDNA and DNA fingerprinting on a broader array of species for understanding community dynamics and estimating populations.

- Develop new tools and expand our capacity for early detection of and rapid response to pathogens brought by nonindigenous species or independently introduced and the impact of those pathogens on native species.

- Improve detection and monitoring capabilities for nonindigenous species by utilizing eDNA, remote sensing, remotecontrolled vehicles, biologging, and other methods coupled with simultaneous measurements of environmental parameters to characterize the differences in invaded and uninvaded communities.

- Expand our capacity for risk assessment and for using optimal strategies to manage invasive species, diseases, and pathogens.

- Use the USGS Nonindigenous Aquatic Species database (available at http://nas.er.usgs.gov/) and field and laboratory studies to develop and apply new analytical and modeling tools to assess risks posed by nonindigenous species, to predict changes in their distribution and occupancy rates, and to better understand how nonindigenous species interact within ecosystems.

\section{Goal 3: Improve the understanding of wetland and aquatic ecosystem structure, function, and services}

WARC scientists seek to improve understanding of the relations among environmental drivers and wetland and aquatic habitat characteristics and their floral and faunal communities.

\section{Strategic Actions}

1. Investigate the impact of contaminants on ecosystem structure and function.

- Attributing changes in population size, biodiversity, dispersal, and survival to natural, anthropogenic, or a combination of these contaminant stressors is a fundamental component of WARC research. These assessments are accomplished through laboratory, greenhouse, and field-based experiments; baseline surveys; and long-term monitoring efforts. An expected outcome of the research is the ability to provide resource managers with information needed to control or mitigate the impacts of contaminants and to adapt management strategies for contaminants, both actions across networks of national parks, national wildlife refuges, and marine protected areas.

2. Improve the understanding of multiple, interactive stressor impacts on ecosystem structure and function.

- Wetland and aquatic ecosystems are often threatened simultaneously by multiple stressors including climate change, land-use change, and contamination; however, a comprehensive understanding of the interactive influences of these stressors on ecosystem structure and function is lacking. Improved understanding of how ecosystem structure and function change in response to multiple stressors can be accomplished through a combination of manipulative experiments, long-term monitoring, spatial analysis, modeling, and paleo- and forensic ecology. Quantifying the mechanisms of multiple stressor impacts will support more comprehensive and accurate process-based models used to guide adaptive management through a clearer recognition of key uncertainties. 
3. Quantify "environmental flows" to understand the impact of altered hydrologic regimes on ecosystem structure and function.

- The ability to assess and forecast ecological responses to changes in hydrologic regimes forms a key component of sustainable resource management in aquatic and coastal systems. Specifying the water needs of species in freshwater ecosystems is a task complicated by the natural temporal and spatial variability of hydrologic regimes. Coupling ecological and hydrologic models will relate population responses to streamflow metrics.

4. Couple habitat and population models to form a comprehensive understanding of ecosystem structure and function.

- WARC scientists will develop wetland and aquatic ecosystem models to improve understanding of the causal factors underlying ecological change and provide insight into how management practices can influence ecosystem and habitat responses to future stressors.

\section{Future Directions}

In the coming years, WARC-led projects will place a greater emphasis on ecosystem-level investigations that quantify the influence of environmental drivers on flora and fauna in rivers, wetlands, estuaries, and offshore ecosystems.

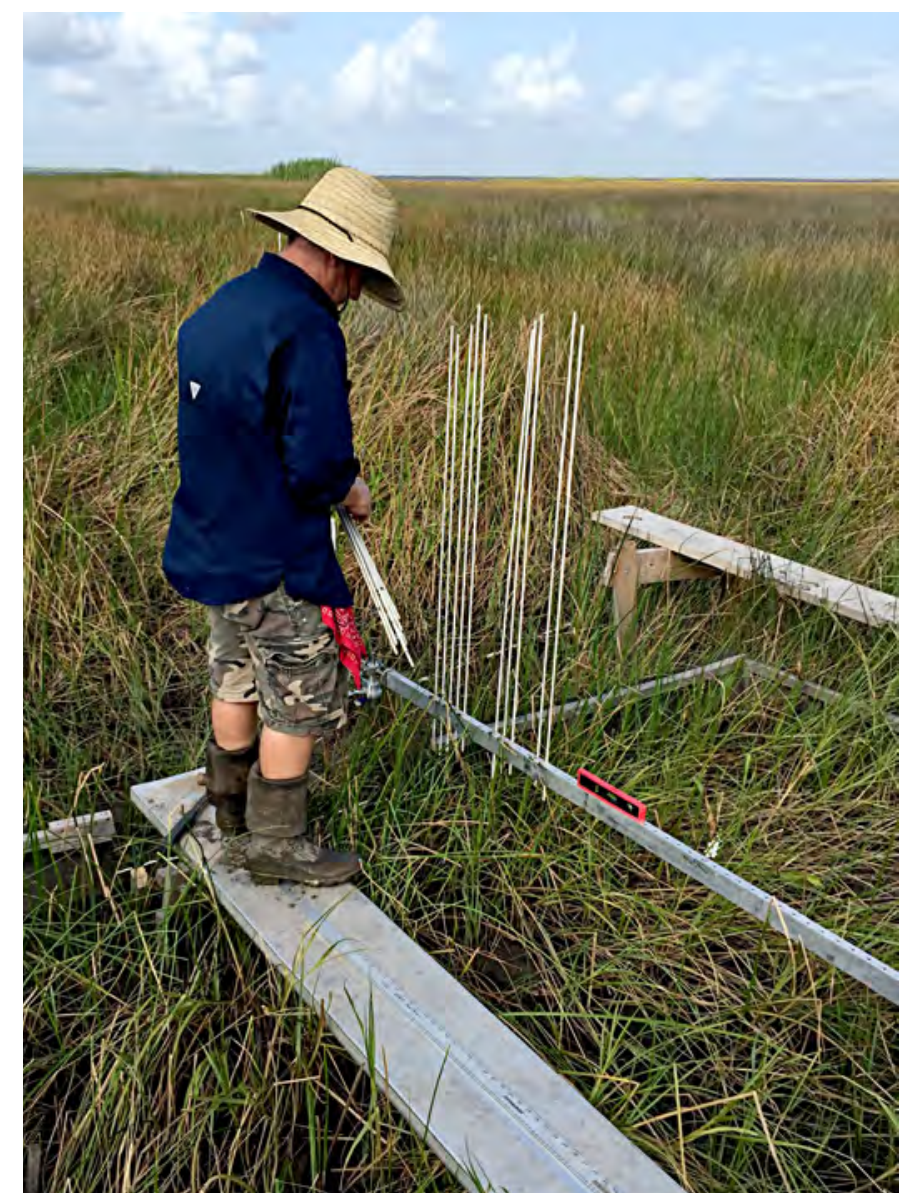

- Expand capacity to understand wetland and aquatic system responses to widespread stressors such as hypoxia, ocean acidification, increased nutrients, contaminants, freshwater depletion, and salinization.

- Increase the understanding of the changing characteristics of fish and wildlife habitats, connectivity across habitats, linkages between terrestrial and aquatic systems, and the influences of habitat changes on community structure and function through the use of manipulative experiments, spatial data analyses, multispecies monitoring approaches, modeling, and animal biomarkers from multiple trophic levels.

- Develop new tools, including stable isotope analyses, paleo-ecological soil core analyses, and interpretation of historical aerial photography or satellite imagery, to improve the understanding of coastal habitat change in response to stressors, such as relative sea-level rise, storm disturbance, and altered hydrology.

- Increase capacity to quantify ecosystem functions (ecosystem "services") that are valuable to society (for example, coastal protection and natural hazard reduction through green infrastructure, water quality improvement via biogeochemical cycling, mitigation of greenhouse gas emissions via carbon sequestration, and fisheries-ecosystem linkages).

\section{Goal 4: Provide the science needed to better characterize, monitor, and prepare for the ecological effects of climate and land-use change}

Given the magnitude of change that is expected in the coming century, there is a pressing need for WARC scientists to provide natural resource managers with the science needed to better understand, anticipate, and prepare for the ecological effects of climate and land-use change. 


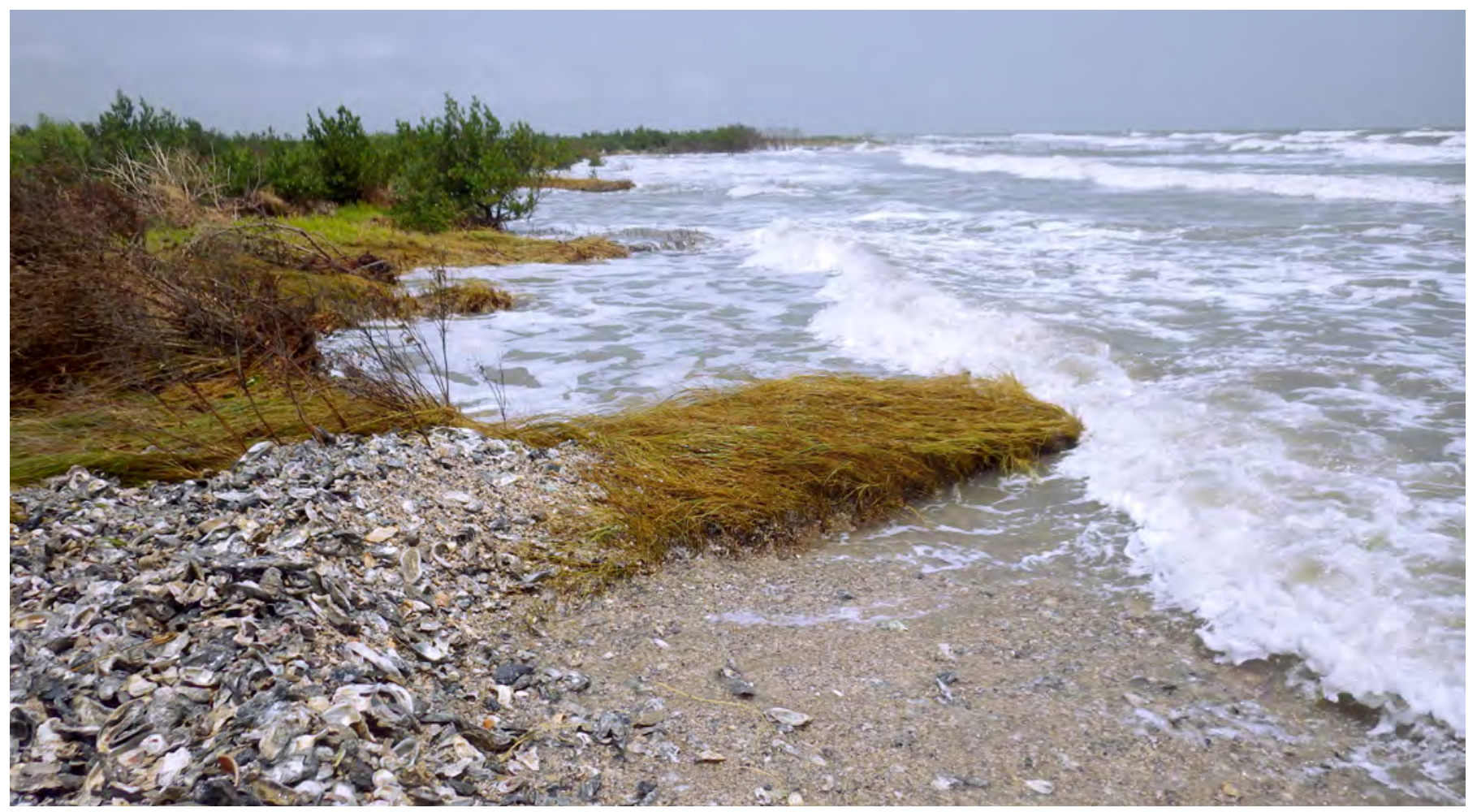

\section{Strategic Actions}

1. Enhance the understanding of physiological responses to climate and land-use impacts.

- Climate and land-use change impact species on the individual level. How they affect the relations of the species and potential species within populations and communities is critical for prediction and management, so a more refined understanding of physiological responses is required.

2. Advance understanding of ecological resistance, resilience, and adaptation in response to climate and land-use change.

- Research in this arena includes the identification and characterization of ecological thresholds, ecological regime shifts, and adaptation strategies. This information will be used to develop future-focused strategies to enhance the management, conservation, and restoration of priority ecosystems and species.

3. Document, model, and predict biological responses to climate and land-use change.

- Special attention will continue to be directed towards increasing understanding of the interactive effects of sea-level rise, altered temperature regimes, acidification, changing rainfall regimes, elevated levels of carbon dioxide, and changes in the frequency and intensity of extreme events including storms.

4. Increase the effectiveness of long-term monitoring and manipulative experimental studies.

- WARC scientists will utilize innovative methods to design monitoring strategies and to collect data for identifying ecological responses. These datasets will then be used in developing predictive models and conducting ecosystem vulnerability assessments to climate and land-use change. 


\section{Future Directions}

- Increase interdisciplinary capacity in research that increases understanding of ecological resistance, resilience, and adaptation in the face of climate and land-use change.

- Maintain and expand upon WARC's collective expertise in ecosystem responses to climate and land-use change (for example, by using WARC climate-controlled greenhouse facilities).

- Develop a better understanding of scale in ecological response, especially related to atmospheric exchanges, and climate and land-use change effects on carbon, water, and nutrient cycling in coastal and marine ecosystems.

- Reconstruct paleoclimates from tree rings, pollen cores, corals, and other biota.

- Forecast and predict ecological effects of climatic events and change by using modeling techniques and specifically addressing vulnerability and resilience.

\section{Goal 5: Apply interdisciplinary science to enhance strategies for management, conservation, and restoration of ecosystems}

Interdisciplinary science is needed to achieve the best design of monitoring strategies and for assessing the effectiveness of restoration actions that support adaptive management. Challenges include the development and integration of novel approaches to research, monitoring, modeling, and adaptive management to support needs of the restoration community.

\section{Strategic Actions}

1. Combine physical and biological studies with ecosystem assessments.

- Assessments will include the integrated study of ecosystem processes (for example, energy flow, materials cycling, competition, predation, and habitat selection) and their interaction to inform management strategies. Plant community dynamics and their interactions are critical for understanding how geomorphic processes shape the coastal community. Projects will examine the cumulative influences of these processes on natural and human-altered ecosystems. Coastal

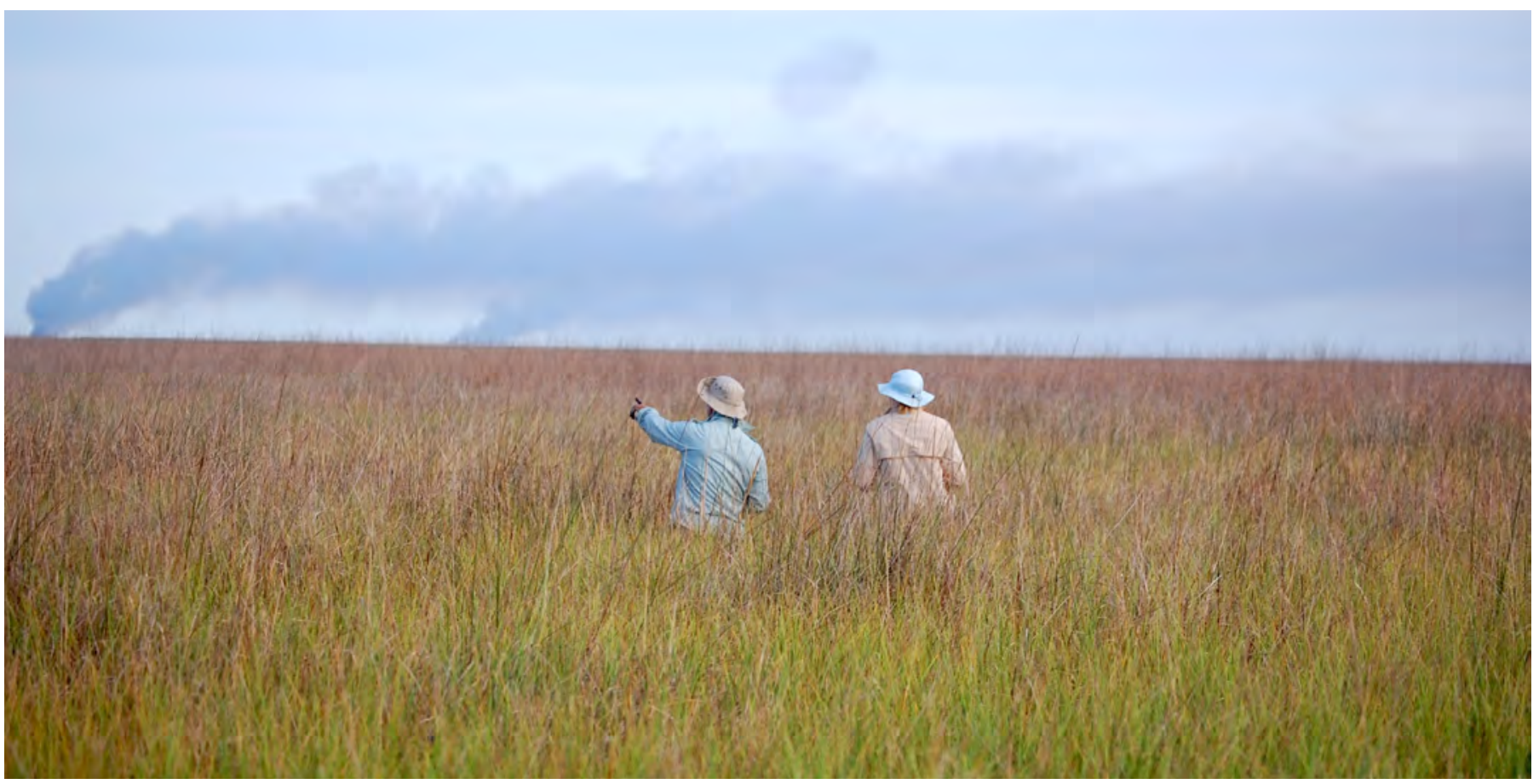


physical processes such as hydrodynamic and sediment transport will be integrated with ecosystem processes to provide information for management actions.

2. Integrate hypothesis-driven research with monitoring to assess restoration alternatives and management actions.

- To support the goals of restoration, there is a need for teams from a broad array of disciplines within WARC, including water and soil science, plant and animal population and community ecology, social science, genetics, statistics, and computer science, to work together to develop long-term monitoring networks coupled with numerical models. Working as integrated teams will provide effective ways to characterize actual system response to restoration and management actions and the ability to forecast expected benefits. Monitoring data will be used to assess performance and parameterize models needed to explore management alternatives. Coupling monitoring and interdisciplinary models at project and landscape scales will promote integrated ecosystem assessments and can improve our understanding of cumulative effects on the natural and human environments.

3. Utilize adaptive management and decision support tools to reduce restoration risk by addressing critical uncertainties.

- State-of-the-art decision support tools used to study restoration scenarios will typically link two or more types of techniques from different disciplines. A major effort will be to reduce uncertainty to improve predictive ability. WARC models can be used to forecast ecological damage loss or change associated with storms, for example. Resource managers will be engaged early on in formalized and strategic approaches for decision making to enhance successful conservation and restoration practices.

\section{Future Directions}

- Increase capacity to employ interdisciplinary research teams, take advantage of diverse sources of data, apply modeling across disciplines, and implement landscape-relevant investigations that provide mechanistic insight.

- Expand capabilities to incorporate field-based and remotely sensed data into decision support tools to address questions at multiple spatial and temporal scales.

- Develop new tools, technologies, and capabilities to assist managers of ecosystem conservation and restoration projects. New efforts will focus on engaging DOI partners in development and optimization of state-of-the-art spatial analyses and future conditions of climate, sea level, and land use for management, conservation, and restoration actions.

- Quantify return on investment across different restoration, management, and conservation scenarios with a focus on economic, ecological, and socioeconomic outcomes.

\section{Goal 6: Provide science to improve ecological understanding and enhance landscape- and seascape-scale strategies for ecological management, conservation, and restoration}

We live in a rapidly changing and interconnected world where landscape- and seascape-scale perspectives and analyses are increasingly needed to enhance efforts to manage, conserve, and restore ecosystems and populations. WARC scientists have a rich legacy of applying landscape science to improve ecological understanding and enhance environmental management across a variety of spatial scales. The aim of interdisciplinary work in this arena is to provide a perspective that spans various spatial (local, regional, and global) and temporal (past, current, and future) scales. Scientists at WARC employ diverse data sources to better understand, model, and predict the causes and ecological consequences of landscape pattern and spatial heterogeneity. 


\section{Strategic Actions}

1. Characterize and understand the movement of organisms, the distribution of populations and communities, and the role of connectivity among and within ecosystems.

2. Improve understanding of the impacts of natural and anthropogenic disturbances on landscape connectivity (or fragmentation) and ecosystem structure and function.

3. Use landscape- and seascape-scale studies to increase understanding of ecological regime shifts and resilience and adaptive capacity to global change.

4. Provide a perspective that spans multiple spatial and temporal scales to improve landscape-scale conservation, management, and restoration.

\section{Future Directions}

- Develop innovative ways to characterize and model spatial and temporal ecological patterns that are relevant to management, conservation, and restoration decisions. Landscape ecology should be employed to tackle problems by using interdisciplinary collaboration and to help research teams work across various spatial (local, regional, and global) and temporal (past, current, and future) scales.

- Identify opportunities for new, innovative collaborations among scientists with different expertise. Seek sources of funding to support interdisciplinary proposals for landscape research.

- Increase capacity to bridge the gap between remotely sensed and field-based ecological methods.

- Increase capacity to use landscape science to inform landscape-scale conservation planning and design.

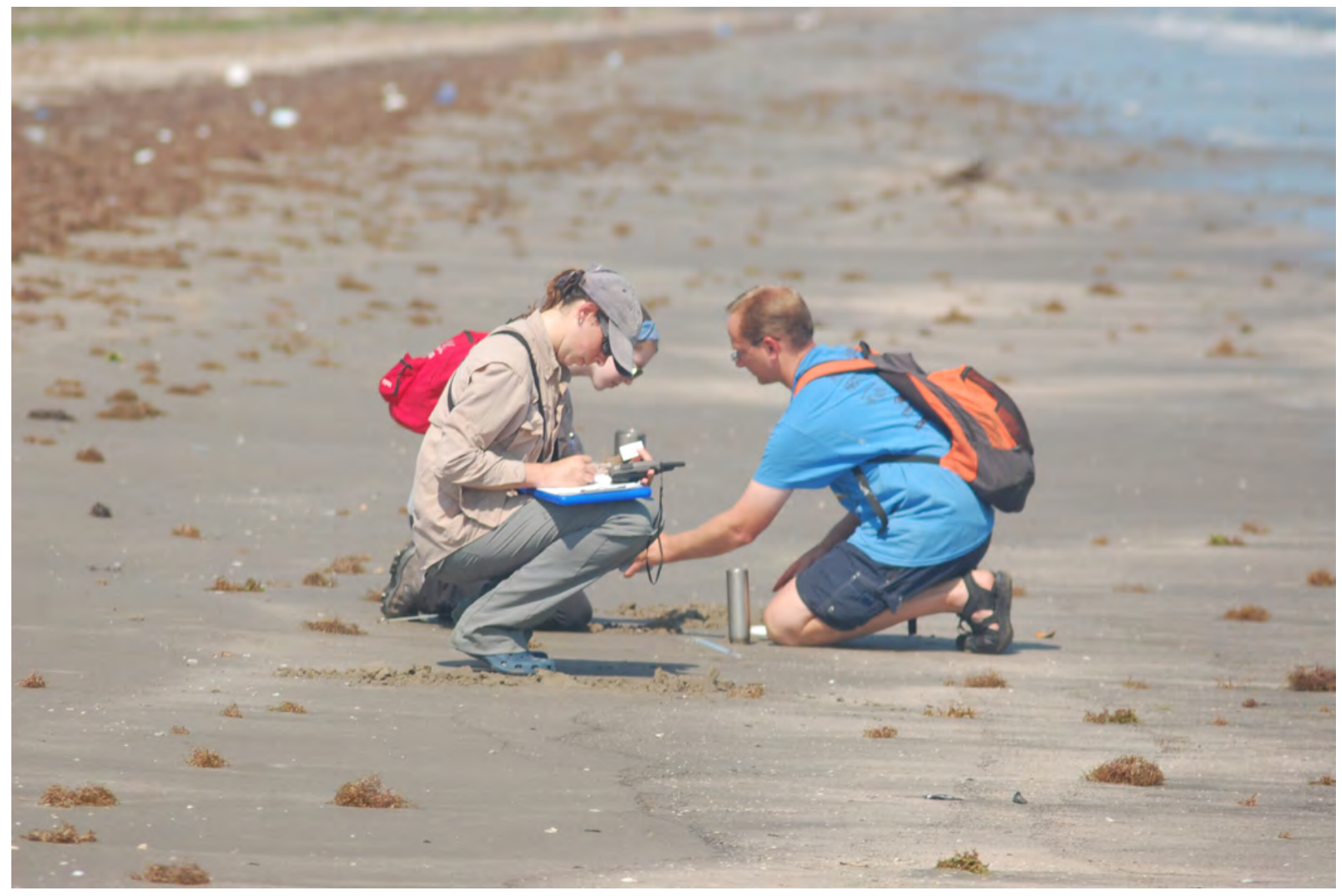




\section{Acknowledgments}

Many thanks go to the WARC "Science Planning Team" for willingly agreeing to be authors and for their insightful thoughts and the many hours spent outlining, writing, and reviewing this strategic science plan. Those team members are Jacoby Carter, Craig Conzelmann, Don DeAngelis, Vic Engel, Gary Mahon, Mike Osland, Caroline Rogers, Stephanie Romañach, Camille Stagg, Greg Steyer, Steve Walsh, and Scott Wilson.

Primary sources of reference while developing this document were strategic science strategies for the USGS and for the Ecosystems Mission Area.

\section{References}

Douglas, M.S., 2007, The Everglades—River of grass (60th ed.): Pineapple Press, 447 p.

Moretzsohn, F., Sánchez Chávez, J.A., and Tunnell, J.W., Jr., eds., 2016, GulfBase—Resource database for Gulf of Mexico research: Accessed November 1, 2016, at http://www.gulfbase.org.

Nicholls, R.J., Wong, P.P., Burkett, V.R., Codignotto, J.O., Hay, J.E., McLean, R.F., Ragoonaden, S., and Woodroffe, C.D., 2007, Coastal systems and low-lying areas, in Parry, M.L., Canziani, O.F., Palutikof, J.P., van der Linden, P.J., and Hanson, C.E., eds., Climate change 2007-Impacts, adaptation and vulnerability. Contribution of Working Group II to the Fourth Assessment Report of the Intergovernmental Panel on Climate Change: Cambridge, U.K., Cambridge University Press, p. $315-356$.

U.S. Geological Survey, 2007, Facing tomorrow's challenges-U.S. Geological Survey science in the decade 2007-2017: U.S. Geological Survey Circular 1309, x + 70 p. [Also available at http://pubs.usgs.gov/circ/2007/1309/.]

Williams, B.K., Wingard, G.L., Brewer, Gary, Cloern, J.E., Gelfenbaum, Guy, Jacobson, R.B., Kershner, J.L., McGuire, A.D., Nichols, J.D., Shapiro, C.D., van Riper III, Charles, and White, R.P., 2013, U.S. Geological Survey Ecosystems Science Strategy-Advancing discovery and application through collaboration: U.S. Geological Survey Circular 1383-C, 43 p. [Also available at https://pubs.er.usgs.gov/publication/cir1383C.] 
Publishing support provided by Lafayette Publishing Service Center 



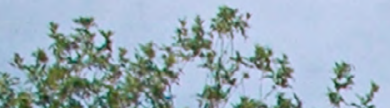

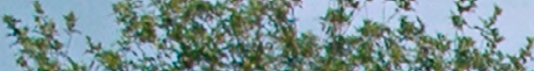

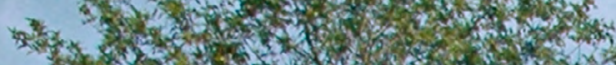

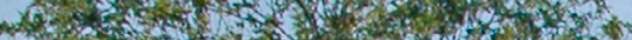

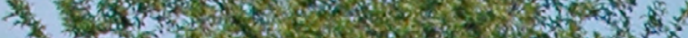

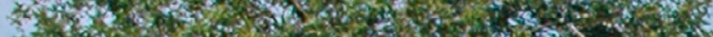

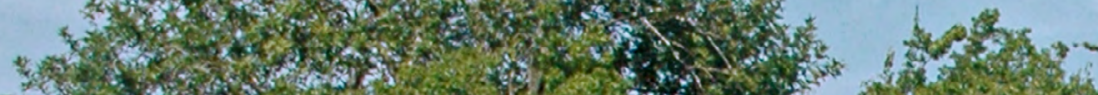

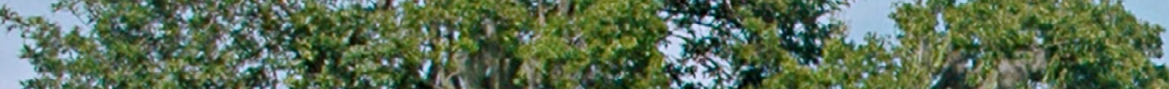

*

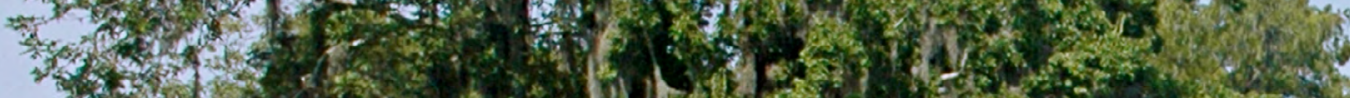

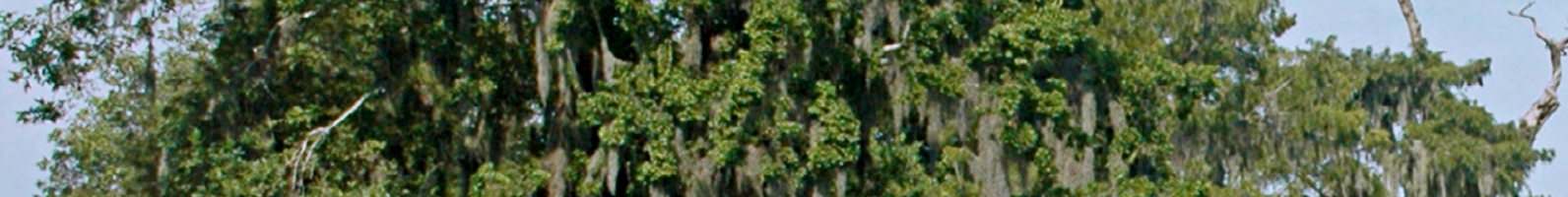

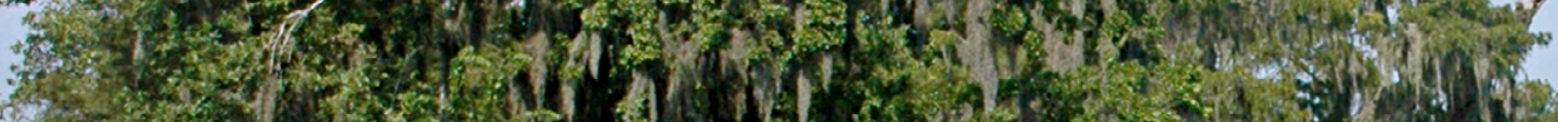

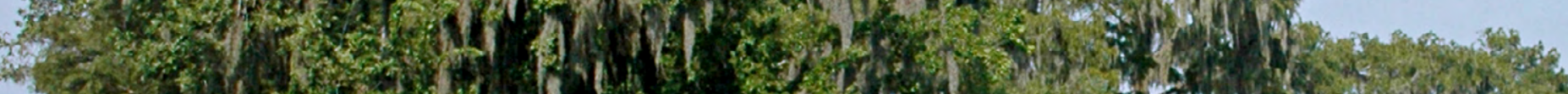

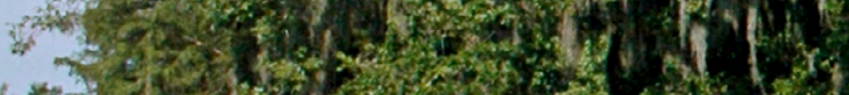
3is. 2.

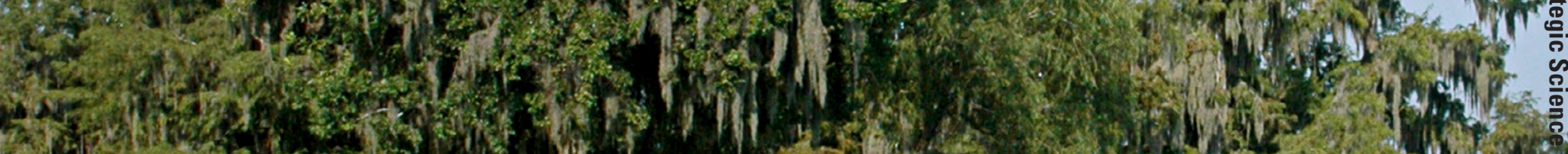
$x_{3}$ g. 